\title{
A educação popular entre a modernidade e a pós-modernidade
}

\author{
Mauricio Mogilka ${ }^{1}$
}

\section{RESUMO}

Este artigo tem intenção de discutir uma possível metodologia baseada no projeto ético-político libertador. Nesta perspectiva, este texto pretende contribuir para a reflexão e a estruturação metodológica de práticas em educação popular. Ele analisa as principais características do trabalho social com a população que tenha o projeto de libertação como referência. A opção metodológica utilizada na produção do artigo foi uma proposta reflexivo-existencial, ou seja, uma reflexão rigorosa sobre a experiência do autor com a intervenção social. $\mathrm{O}$ artigo conclui afirmando que: propostas de práxis mais radicais precisam superar a desnecessária oposição modernidade $\mathrm{x}$ pós-modernidade, agregando elementos emancipatórios de ambos os movimentos; os mediadores críticos precisam desverticalizar as relações com os grupos populares; precisamos desenvolver o otimismo crítico e superar o pessimismo que frequentemente acompanha a atividade da crítica.

Palavras-chave: Educação Popular; Metodologias da Libertação; Paradigmas de Trabalho Social.

\section{Popular education between modernity and post-modernity}

\section{ABSTRACT}

This article aims to make a discussion about of the possible methodology supported in the liberator ethical-political project. This article aims to contribute to the reflections and the construction of practices in popular education. The text analyses the main factors of the social work that has the liberation project like its reference. It also demonstrates how the more radicals propositions of popular education and of practices need to overcome the opposite modernity $\mathrm{x}$ postmodernity, joing liberations factors of both movements.

1 Doutor em Educação pela Universidade Federal da Bahia - UFBA. Professor Associado de Didática da Universidade Federal da Bahia.. Coordenador e mediador do projeto de extensão Educação, teorias críticas e processos emancipatórios. Desenvolve o projeto de pesquisa Governos progressistas na América Latina e seus impasses em contexto neoliberal. Email: mmogilka@ufba.br 
Keywords: Popular education. Liberation Methodologies. Paradigms of Social work

\section{Educación popular entre la modernidad y la pos-modernidad}

\section{RESUMEN}

Este artículo tiene el objectivo de discutir una posible metodologia basada em el projecto ético-político libertador. En perspectiva, el texto pretende contribuir para la reflexion y la a estruturación metodológica de prácticas em educaçión popular. Ele analisa las principales características del trabajo social com la población que tenga el projecto de liberación como referencia. Além disto intenta demonstrar como propuestas de educación popular e de práxis más radicales necesitan superar la desnecessária oposición modernidad x pós-modernidad, agregando elementos liberadores de dos movimientos.

Palabras clave: Educación Popular; Metodologias de la Liberación; Paradigmas de Trabajo Social.

A esperança sempre foi uma das forças dominantes das revoluções e das lutas sociais; eu ainda sinto a esperança como a minha concepção de futuro.

Jean-Paul Sartre

Se você é capaz de se indignar com uma injustiça cometida contra qualquer ser humano, em qualquer parte do mundo, então eu e você somos companheiros.

Ernesto Che Guevara

\section{Educação popular e o projeto ético-político da libertação²}

Muito se tem falado e questionado quanto à validade, natureza e reais resultados alcançados pelas atividades de intervenção social, universitárias ou realizadas por outras organizações. Como qualquer campo de atividade humana, elas também estão sob questionamento e análise

2 A opção metodológica utilizada na produção deste artigo foi uma proposta reflexivoexistencial, ou seja, uma reflexão rigorosa sobre a experiência do autor com a intervenção social e com a militância política ao longo dos últimos trinta anos. Nesta opção, há um diálogo com alguns textos teóricos, indicados nas referências deste artigo. Estes textos ajudaram a fazer uma análise crítica da experiência. Outro elemento importante desta metodologia foi 
constantes, inclusive porque estes questionamentos representam um dos mais importantes fatores para a reflexão e o avanço das ações sociais.

É justamente este constante questionamento que permite aos grupos que atuam neste campo trabalhar para superar problemas persistentes na área, entre os quais poderíamos citar como os mais urgentes: 1. Baixo financiamento estatal e insuficiência de políticas públicas na área; 2. Assistencialismo; 3. Ação sem apoio teórico e reflexivo; 4. Despreocupação com o desenvolvimento subjetivo dos envolvidos; 5. Autoritarismo na relação com os grupos populares; 6 . Idealização das comunidades e da cultura popular.

Os movimentos sociais apresentam uma enorme riqueza de situações, problemas e contradições para as quais as próprias práticas dos movimentos não podem preparar integralmente. Por isto as atividades de intervenção social crítica são potenciais oportunidades para ampliar a capacitação profissional, expandir a consciência crítica sobre os dilemas da prática e desenvolver mais amplamente as habilidades educativas dos integrantes dos movimentos sociais. Estas atividades são momentos onde é possível aprofundar temas específicos, nascidos da experiência prática, mas não esgotáveis por ela.

Por esta capacidade singular de unir teoria, prática e sensibilidade, as atividades de intervenção social crítica, área onde atuo há mais de trinta anos, são fundamentais como instrumentos para se construir sociedades mais justas. Ainda mais no contexto atual, com o retrocesso nas pautas de cidadania e a eleição de um governo de extrema-direita no Brasil em 2018.

Por isto, os projetos de intervenção social nas linhas críticas têm grande potencial para se constituir como espaços de participação democrática. Ou seja, um local público onde as pessoas possam se reunir para debater idéias, dialogar sobre questões sociais e elaborar alternativas de ação, ao mesmo tempo que desenvolvem suas subjetividades e

o aproveitamento do contato dialógico e aberto com os agentes sociais e grupos populares atendidos nestas três décadas: eles foram um fator humano de constante aprendizagem para o autor. Finalmente, esta metodologia de construção do texto se coloca claramente como produção textual de caráter político e não-neutro. Contudo, político aqui não significa político partidário ou doutrinário, mas ético-político: um discurso ou uma prática que analisa as contradições da realidade, se emancipa de mistificações, propõe alternativas e as coloca em prática coletivamente. Faz isto corajosa e dignamente, pois sabe que toda alteração do real envolve riscos. 
sua consciência crítica. ${ }^{3}$ Estes espaços tendem a gerar práxis, ação transformadora, mas associam isto com o desenvolvimento subjetivo dos envolvidos. Isto impede que a práxis se decomponha em práticas de luta duras e cristalizadas, que endurecem os participantes e, por se tornarem rígidas, são com o tempo dominadas pelos grupos opressores.

Nestes espaços, o debate pode frequentemente se estabelecer fora do controle do poder instituído, de tal forma que o logos coletivo seja poiético, isto é, capaz de gerar ação criativa e não rotineira. Deste modo, as coletividades podem gerar novos sentidos e novas soluções para as contradições sociais vividas no duro cotidiano capitalista, bem como novas formas de enfrentamento com os poderes conservadores.

Estes espaços de participação democrática podem desempenhar um papel importante na luta contra diferentes formas de exclusão. Estes espaços podem se converter em verdadeiros momentos de imaginação social, onde se desenvolvam modalidades alternativas de interpretar e recriar as relações e as práticas sociais. ${ }^{4}$ Através do exercício da imaginação social, os grupos populares encontram um local e um momento para construir possibilidades de sociedades mais justas, humanas, igualitárias e éticas, ${ }^{5}$ e descobrir quais seriam os caminhos e lutas para que estas sociedades sejam possíveis. Trabalhando com fundamento nas teorias políticas mais engajadas, estes momentos de imaginação social reúnem, junto com a população, diferentes sujeitos, como educadores, artistas, acadêmicos e ativistas sociais, de modo a explorar possibilidades de reforma e de transformação em diferentes espaços sociais.

Para isto, neste artigo o paradigma chamado educação popular e seu enfoque complexo da política e da ação social será considerado um instrumento para compreendermos mais profundamente o momento que vivemos e contribuir para que os movimentos sociais superem os impasses em que estamos, com um forte avanço das forças neoliberais e

30 desenvolvimento da consciência crítica é um dos fenômenos mais importantes na educação popular. Sendo complexo, não pode ser definido por um conceito apenas. Por isto poderíamos definir consciência crítica como aquela que: 1. Coloca discursos e práticas em questão, superando a ingenuidade; 2 . Estabelece relações de causa e efeito; 3 . Compreende amplamente e não apenas focalmente; 4 . Busca a causalidade remota dos acontecimentos locais (pois consegue dar o salto do real empírico para o real estrutural); 5 . Permite a tomada de consciência da situação real vivida pelo grupo.

4 Neste artigo, alternativo significa aquilo que conseguiu superar os valores e às práticas de reprodução do capitalismo ou a outras propostas opressivas de qualquer natureza.

5 O significado de ética, aqui, não se resume a seguir regras, leis ou normas socialmente instituídas, mas diz respeito às ações e políticas que têm relação direta com o bem estar e os direitos de todos os seres humanos, e se pautam por este princípio em suas estratégias. 
até de extrema-direita e retrocesso nos direitos. $\mathrm{O}$ artigo tentará mostrar que a complexidade é um imperativo para a transformação da realidade. Enfrentamentos baseados em cosmovisões simplistas, reducionistas e hierárquicas, herdadas da própria modernidade, mesmo que progressista, têm sido dominados pela eficiente máquina política neoliberal.

Em função destas questões, um dos objetivos deste artigo é estimular a nossa imaginação criadora, para pensarmos os subsídios de um projeto de país para o Brasil. Obviamente o objetivo aqui é pensar este projeto fora dos marcos neoliberais, mas também superando os limites do pensamento da esquerda mais ortodoxa e verticalista, e sua enorme dificuldade de dialogar com o povo.

Neste último caso, os projetos políticos tem sido mais reativos ao neoliberalismo do que propositivos. Ou então, têm sido elaborados a partir de uma rígida leitura da teoria de estado marxista, e mais frequentemente, leninista. Tais projetos têm pouca chance de responder aos dilemas atuais de uma América Latina marcada pela agenda excludente das políticas neoliberais, e agora, articuladas com a ascensão da extrema-direita.

Um outro objetivo deste artigo é que os nossos projetos de intervenção social se transformem em momentos onde o grupo exercite o pensar o novo. Ou seja, pensar e ultrapassar os limites já conhecidos sobre o trabalho social e sobre as grandes questões sociais no Brasil e na America Latina. ${ }^{6}$ Assim, os participantes encontram estímulos para compreender e deslocar estes limites, projetando o trabalho e os movimentos sociais para outra potência, outras fronteiras, outros patamares.

Este artigo visa demonstrar, que a educação popular é um dos paradigmas adequados para se fazer intervenção social dentro do horizonte ético-político colocado anteriormente. A educação popular faz parte das teorias latino-americanas da libertação, junto com a teologia, a sociologia, a psicologia e a filosofia da libertação e o teatro do oprimido. ${ }^{7}$ Estas teorias são utilizadas em uma grande quantidade de países

6 Trabalho social é definido aqui como aquele que se volta para atender demandas públicas de setores da população, especialmente seus setores mais pobres. Envolve também processos de exclusão não necessariamente econômicos: exclusão étnico-racial, de gênero e sexualidade, geracional, cultural. Se desenvolve geralmente nos equipamentos das políticas públicas (CRAS, CREAS, CAPS, unidades básicas de saúde, escolas públicas), em ONGS, em movimentos sociais, em projetos de extensão universitária.

7 Libertação do ser humano significa: libertação de todas as pessoas de uma sociedade, de todas as carências materiais, a não ser aquelas que atingem a todos, indistintamente; libertação de todas as formas de opressão política, de todos os privilégios e, por extensão, 
do terceiro mundo. Contudo, ainda são insuficientes as oportunidades de capacitação para os educadores e ativistas sociais brasileiros terem acesso de forma intensiva e extensiva a estas teorias. A demanda é muito superior ao que as universidades têm oferecido. Ainda mais quando estas oportunidades têm caráter formativo e também de intervenção na realidade.

As idéias principais e as metodologias sugeridas pelas teorias da libertação estão claramente na contracorrente das forças políticas neoliberais e desumanizadoras da atual fase das sociedades capitalistas como a nossa. Trata-se de um pensamento libertário, profundo, amoroso, radical, mobilizador, revolucionário, anticolonialista. Suas contribuições são inestimáveis no campo da alfabetização, formação, intervenção social, auto-organização de comunidades. É imenso o seu valor para pensar as práticas sociais e as idéias que fundaram o que chamamos de Brasil e América Latina, que são a nossa origem, nosso caldo cultural e nosso horizonte de felicidade.

A educação popular, assim como as demais teorias da libertação, nasceu em plena modernidade, a partir do fim dos anos 50. Estas teorias-práxis agregaram importantes elementos emancipatórios da modernidade, como a consciência crítica e a democracia participativa. Contudo, elas também incorporaram elementos que estão além da modernidade, que a ultrapassam e a desestabilizam: incerteza, indeterminação e complexidade, por exemplo. Elas também estão centradas na afetividade e na solidariedade como fundamentos da vida coletiva digna, rejeitando a competição e individualismo como orientadores da vida social. ${ }^{8}$ No plano político, as teorias da libertação apostam no basismo e na horizontalidade e não no dirigismo verticalista de vanguardas intelectuais ou políticas.

O conceito educação popular é polissêmico, envolvendo no mínimo dois significados, diferentes e às vezes até antagônicos do ponto

das desigualdades sociais; libertação de todas as limitações de acesso à cultura, à saúde e à educação de qualidade; libertação da escravidão mental, representada por preconceitos de qualquer natureza e por ideologias que visam manter as pessoas, especialmente os trabalhadores, presos aos interesses de outros.

8 Competição e individualismo são dois valores fundamentais da moral capitalista; os outros são: consumismo, alienação política e ética da esperteza. Sem a reprodução destes valores nas pessoas a base de sustentação subjetiva do capitalismo desaba (além da moral, os outros elementos que compõem o poder simbólico são a educação, a cultura, a mídia e a religião). Além do poder simbólico, os outros dois pilares de sustentação do poder burguês são o domínio da economia e o poder político. 
de vista político. Ele pode significar qualquer prática educativa realizada com grupos populares, e aí atuam diferentes paradigmas hoje na America Latina, com intencionalidades políticas distintas. Eu identificaria pelo menos seis: assistencialista, cientificista, marxista-leninista, institucionalista, libertador, e paradigma da inclusão social.

Um segundo significado, mais restrito, é usado pelos trabalhadores sociais e educadores populares para designar as praticas educativas desenvolvidas com a população a partir da metodologia e princípios libertadores, principalmente ligado ao pensamento de Paulo Freire e seus colaboradores. Nota-se que no primeiro caso trata sobre a educação não-formal no sentido amplo: toda experiência social que modifique valores, atitudes, capacidades ou conhecimentos do grupo, em qualquer direção. No segundo caso, trata de um significado mais específico: educação não-formal com caráter crítico-emancipador-humanizador.

Fazer esta distinção é fundamental, e às vezes ela não é feita, dando a impressão que toda prática educativa com o povo é sempre emancipadora. Isto oculta a presença dos paradigmas menos compromissados com uma transformação social mais profunda, como o assistencialista e o inclusivo. Este último, por exemplo, é largamente utilizado hoje, especialmente pelas organizações sociais ligadas ao terceiro setor (braço do capital na área social). Ele tem algumas características quase antagônicas aos paradigmas mais críticos, especialmente o libertador, o institucionalista e o marxista-leninista (embora estes três se diferenciem em alguns pontos também).

No caso da inclusão social, podemos identificar um novo paradigma de educação popular na America Latina. Antes é preciso definir que o paradigma da inclusão social, como está sendo denominado aqui, não trata da inclusão de pessoas com deficiência, mas da inclusão dos grupos sociais excluídos socialmente, sem alterar substantivamente as estruturas sociais. Ele traz algumas características do desenvolvimentismo integracionista da década de cinquenta e do tecnicismo dos anos sessenta, atualizadas e agregadas com características do nosso tempo, especialmente neoliberais. Ele surge com a explosão das ONG's, na década de 1990. Ele coloca a equipe como o sujeito do processo educativo, e não o grupo popular participante. Isto está implícito em seus manuais e projetos de intervenção, e jamais explícito, mas aparece nas práticas realizadas, se observarmos com atenção. 
Seus manuais e técnicas são freqüentemente de origem empresarial e norte-americana, e sua intencionalidades carecem de uma crítica estrutural à sociedade. Segundo este paradigma, na sua visão neotecnicista, mobilização, capacitação, criticidade, são resultado de questões técnicas e cognitivas. Uma vez capacitada cognitiva e tecnicamente, a população será capaz de conquistar a sua cidadania. Isto desconsidera os outros fatores contextuais que afetam as lutas por direitos.

Como vemos, são muito diferentes as práticas e os paradigmas do que se tem chamado imprecisamente de educação popular. Muitas vezes estas práticas têm significados políticos até antagônicos, devido às implicações políticas dos grupos e instituições que estão sustentando ou financiando aquelas práticas. Daí a necessidade de definição clara quanto ao que estamos chamando de educação popular. Neste texto, estarei trabalhando com o conceito mais específico, aquele ligado às teorias da libertação, como foi definido logo acima.

A partir deste viés, faz-se algumas análises de princípios ético-políticos e metodológicos, e mesmo algumas sugestões, no sentido de enriquecer as já ricas práticas de trabalho com a população, apesar da carência material com que trabalhamos.

O paradigma da libertação tem, entre suas características centrais, o princípio de estimular que o grupo ou comunidade com o qual trabalhamos ocupe o lugar de protagonista do seu processo de crescimento-libertação. ${ }^{9}$ Ou seja, trabalharmos fundamentados, e levando a sério, a finalidade da autolibertação popular. Isto é essencial, se pretendemos mudar realmente alguma coisa, e não produzir novas formas de opressão, ao contestar e superar o poder burguês.

Para que isto ocorra, é necessária uma translação radical de nossa subjetividade, nos permitindo formas de humanização trans modernas. ${ }^{10}$ Ou seja, superar os modelos de subjetividade da modernidade

9 Libertação do ser humano, aqui, significa: libertação de todas as pessoas de uma sociedade, de todas as carências materiais, a não ser aquelas que atingem a todos, indistintamente; libertação de todas as formas de opressão política, de todos os privilégios e, por extensão, das desigualdades sociais; libertação de todas as limitações de acesso à cultura, à saúde e à educação de qualidade; libertação da escravidão mental, representada por preconceitos de qualquer natureza e por ideologias que visam manter as pessoas, especialmente os trabalhadores, presos aos interesses de outros.

10 Humanização é entendida aqui como o desenvolvimento do ser humano em todas as suas capacidades, dimensões e possibilidades, desde que não levem ao sofrimento ou opressão de si mesmo, de outros seres humanos ou outras formas de vida. 
capitalista, com sua ânsia por segurança, certeza, objetivos pré-estabelecidos e metas produtivistas.

Para produzirmos teorias e práticas revolucionárias (que busquem a transformação profunda da realidade social),precisamos superar a desnecessária oposição entre teorias modernas e pós-modernas. Não devemos esquecer que o capitalismo e seus intelectuais se apropriaram nos últimos trezentos anos tanto do movimento moderno-ilumunista como do pós-moderno, mais recentemente.

Nos dois casos, eliminaram as características emancipatórias, preservando o que lhes era interessante, uma vez que estes amplos movimentos são contraditórios, tendo aspectos também inovadores-conservadores dentro de si. Logo, para construirmos teorias que ajudem a revolucionar a realidade, precisamos de epistemologias complexas, que agreguem elementos emancipatórios da modernidade e da pós-modernidade. Que sejam transmodernas: estejam além da modernidade e dialoguem com o movimento pós-moderno, sem estar necessariamente dentro dele.

É importante deixar clara a posição aqui defendida a respeito do lugar da teoria nos processos de transformação do real. Segundo esta posição, a transformação da realidade social é conseqüência da ação humana coletiva, e não de discursos, pensamentos, afetos ou tecnologias. Contudo, as práticas humanas não se convertem em práxis sem o auxílio de discursos, idéias e afetos que transgridam de alguma forma o que está estabelecido pelo sistema opressor.

Para trabalharmos com a finalidade da autolibertação popular, é necessário também que aceitemos trabalhar na ótica da construção coletiva, e não de forma dirigista, já com objetivos e até modelos de sociedade pré-estabelecidos: naquilo que já está definido não pode haver autêntica construção coletiva. Se já temos até o modelo de sociedade e de poder definido, seja pelos nossos valores pessoais, seja pela doutrina política, o que se tem chamado de participação democrática se restringe à execução.

Neste caso, nós, os mediadores e as instituições que nos mantêm, somos os arquitetos, com uma planta arquitetônica já desenhada, e a população é o ajudante, o pedreiro ou no máximo o mestre de obras. Mas se trabalhamos em uma ótica realmente libertadora e de construção coletiva, inclusive o projeto arquitetônico é realizado por todos, e todos participam de todas as fases da construção. Com isto, se supera a alienação do trabalhador e a divisão social do trabalho. Aí se pode fa- 
lar em autêntica participação democrática. ${ }^{11}$ Esta característica dirigista é um dos pontos que distinguem o projeto ético-político libertador, e também o institucionalista, do marxista-leninista (embora haja alguns pontos de convergência). $O$ projeto leninista está fundado na modernidade, embora não seja capitalista.

Para potencializarmos o trabalho de educação popular e estimularmos experiências libertadoras em nosso contexto, é preciso considerar as pessoas da população como seres humanos, com todas as potencialidades que qualquer outra pessoa possua, em outra classe ou situação social. Como disse muito bem Antonio Gramsci, todas as pessoas são capazes de se desenvolver intelectualmente, mas nem todas encontram em uma sociedade capitalista as condições para este desenvolvimento. Quando atuamos de forma dirigista, desrespeitamos a população e este princípio ético.

Esta é uma das mais desafiadoras e mais fascinantes características do projeto da libertação: abandonar o caminho conhecido e vanguardista de dirigir o povo, que desrespeita sua inteligência, por um lado. Mas também perceber que ele precisa de condições para o desenvolvimento subjetivo necessário à humanização-libertação, condições negadas, no caso latino-americano, historicamente desde a colonização. ${ }^{12}$

Por isso, o projeto libertador, que é bem amplo e não se restringe ao trabalho (importantíssimo) de Paulo Freire (2001), consegue integrar nas mesmas práticas tanto a busca da transformação concreta de aspectos da realidade (práxis) como a transformação da subjetividade dos envolvidos, inclusive nós, os mediadores. Nossa humanização é necessária para podermos estimular a humanização-libertação popular: nós não estamos excluídos dos processos que pretendemos instaurar junto com os grupos com os quais trabalhamos.

Nesta concepção, a educação popular inspirada no projeto ético-político libertador busca no mínimo e simultaneamente três finalidades: 1. Criar condições para desenvolvimento da subjetividade popular;

11 Democracia neste artigo refere-se aos processos e às propostas de democracia participativa, direta, e não à manutenção do modelo elitista e anti-participativo de democracia representativa dominante nas sociedades capitalistas; nem tampouco se refere no modelo supostamente participativo vigente nos regimes de socialismo burocrático, partidário e ultracentralizado, como foram o caso da União Soviética ou da Polônia no passado, e atualmente a China ou a Coréia do Norte.

12 A humanização está ligada à libertação, pois a opressão não permite o desenvolvimento pleno de todas as capacidades humanas, que Ihe seriam ameaçadoras. 
2. Fortalecer o poder popular; 3. Estimular a práxis, a partir de demandas relevantes para os próprios grupos populares.

\section{Otimismo crítico e capacidade utópica}

Alguns grupos críticos na área social atuam segundo o princípio "pessimismo no pensamento e otimismo na ação". Não obstante o valor de seus trabalhos, creio que este princípio não faz sentido. Não atuamos para modificar algo sem acreditar nesta possibilidade. A crença na possibilidade de sermos bem sucedidos é essencial para a ação, especialmente quando trabalhamos fora do instituído, para modificá-lo, e enfrentamos as barreiras do sistema, como no caso dos movimentos sociais progressistas. O otimismo é então uma das condições da práxis, e é uma condição subjetiva.

Muitos movimentos na América Latina que modificaram as suas realidades começaram de experiências inicialmente precárias, pequenas e pouco organizadas. Por exemplo, o surgimento do MST nos estados do sul do Brasil em 1979 tem suas raízes muito antes, no trabalho de educação popular de grupos como a pastoral terra, paciente, otimista e perseverante. Também foi assim em Chiapas, já nos anos 1970, levando a um movimento que só constituiria sua potência plena em janeiro de 1994. E na Bolívia, pois a eleição do governo progressista de Evo Morales em 2005 foi possível com o apoio do MAS (Movimento ao Socialismo), resultado de uma reorientação das forças sociais e que começou em um processo de autocrítica iniciado em 1992. Mais remotamente este processo remonta às revoltas da água e do gás, a partir de ano 2000, como conseqüência das novas políticas governamentais bolivianas geradas pelo Consenso de Washington em 1989.

Em todos estes movimentos, alguns grupos juntaram a indignação com otimismo: acreditaram naquilo que parecia impossível, foram visionários. Seus sonhos poderiam dar certo ou não, mas só poderiam saber fazendo a experiência. Ser visionário não é uma característica de gênios, mas de todo ser humano que tenha coragem de enfrentar o pessimismo, tão conveniente ao sistema opressor nestes casos. É importante para ele que acreditemos que não é possível mudar as coisas, que sempre foi assim, que o sistema é mais forte do que as coletividades organizadas. Esta nuvem pessimista não nos beneficia em nada, além de ser comodista. 
Mas o otimismo é muito combatido por alguns grupos e teorias críticas. Otimismo e criticidade parecem travar uma batalha titânica. Uma das razões para isto vem do fato que o otimismo pode ser ingênuo. Aí acaba levando à ilusão, e a ilusão não muda a realidade: produz sofrimento e desencanto. $O$ otimismo ingênuo é um dos alicerces simbólico-afetivos do sistema opressor no campo do trabalho social, que é a área onde atuo deste 1985.

Um outro motivo desta oposição é que a criticidade é negativa em sua essência, e não otimista. Ela tem em seu núcleo, na sua alma, a negação de algum aspecto da realidade. É isto que caracteriza a crítica: a capacidade de duvidar, de pôr em questão, de desconstruir simbolicamente algo instituído, seja uma prática social, um valor, discurso ou forma de poder. E nisto ela é imprescindível à transformação do mundo.

Mas a criticidade pode levar ao pessimismo, pois sua potência é destrutiva e não construtiva. Ser crítico não é atuar, mas superar a ingenuidade. Esta artificial conexão criticidade-ação foi uma armadilha na qual até autores brilhantes como Paulo Freire caíram, com o conceito de conscientização, que inclui consciência crítica e práxis. Mas estas duas coisas não estão juntas necessariamente, e nem por isso um grupo ou movimento social deixa de ser crítico potencialmente. Um grupo ou movimento social não deixa de ser crítico porque não atua. Muitas vezes a reflexão crítica lhe mostra que estrategicamente não é o momento de agir. Sabe esperar o momento adequado para a ação, e construir as condições propícias para isto. É bem diferente da não-ação passiva, naturalizada, resultado do acomodamento à opressão.

Parece que estamos então em um impasse: a criticidade é essencial à práxis; mas ela não produz práxis, especialmente em condições muito adversas. Por outro lado, o otimismo é essencial à ação, mas pode levar a uma análise superficial do contexto de luta social. Para resolvermos este impasse, precisamos integrar criticidade e otimismo, constituindo o otimismo crítico que supera a ingenuidade e permite à crítica aquilo que ela não pode dar: a potência motivadora que leva à práxis, o elemento libidinal-afetivo de toda ação humana ousada e reinstituinte, o motor e o coração da práxis humana.

A criticidade pode assumir pelo menos quatro formas distintas: uma forma queixosa, que desagua no máximo na denúncia. Uma outra forma que eu chamaria de centrífuga, que detona toda e qualquer forma de autoridade, independente de seu caráter democrático ou não. 
Esta é comum nos jovens e é uma etapa importante no seu processo de amadurecimento e do tornar-se adulto. Mas ela precisa se converter na quarta forma, pois embora importante, não elabora proposições para modificar as coisas criticadas. É visível na atitude de "chutar o pau da barraca".

A terceira forma seria a criticidade analítica. Muito comum em pesquisadores e professores universitários, é tributária de uma consistente leitura teórica e reflexiva da realidade, geralmente feita a partir de teorias críticas, mas não propositivas. Esta criticidade conduz a apreciações rigorosas da realidade, mas não está ligada à práxis, por estar ancorada no pessimismo. ${ }^{13}$

Finalmente a quarta forma seria a criticidade ativa. A criticidade não é ativa em si mesma. Ela se converte nesta forma pela integração com outros elementos, entre os quais o otimismo joga um papel importante, como afirmado acima. Esta é a forma mais perigosa para os poderes opressivos, e é um dos elementos para que se constitua uma etapa importante da práxis, a proposição de alternativas:

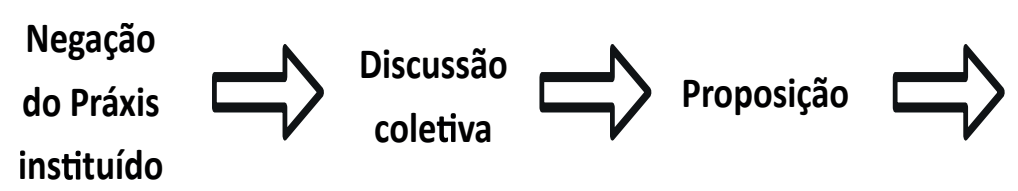

Sem o otimismo em conjunto com outros elementos, a primeira etapa, que é a alma da criticidade, e a segunda, podem ocorrer. Mas dificilmente ocorrerá a terceira, essencial para aquele movimento social chegue à práxis.

Sem otimismo crítico não existe utopia, e sem esta criação imaginária de novas propostas para a vida dificilmente haverá práxis. Isto é ainda mais importante quanto mais as condições são adversas. Esta criação simbólica guia as coletividades humanas por meio de um caminho que parece pouco promissor, analisando apenas suas condições concretas atuais.

Tentar extinguir o otimismo ligado à mudança da realidade é um mecanismo simbólico comum nas estratégias conservadoras, uma vez que usando apenas a coação física e o poder econômico não é possível estabelecer domínio prolongado sobre toda a sociedade. A per-

13 Consegui identificar esta forma de criticidade a partir dos debates e reflexões com os agentes sociais participantes dos projetos de extensão nos quais atuo. 
manência e difusão da capacidade utópica é uma contra-prática libertadora.

Creio que há algumas condições nas nossas sociedades que favorecem a expansão das utopias. Uma delas é clareza do projeto ético-pessoal: superação da opressão dentro de nós mesmos. Investigar qual é realmente a nossa posição diante do poder instituído. Muitas vezes reclamamos do instituído, mas não percebemos que colaboramos com sua permanência. $\mathrm{O}$ que realmente está estruturado neste microcosmo que eu chamo de "eu"?

Uma coisa que sempre me impressionou foi a força e segurança de algumas pessoas diante da opressão quando não a tem dentro de si, sua serenidade no enfrentamento quando outros tinham medo e expectativas desfavoráveis. Martin Luther King, Nelson Mandela, Bob Marley, Paulo Freire e Don Helder Câmara foram ativistas que tinham isto em alto grau. Outra condição favorecedora das utopias e práxis é o conhecimento de experiências alternativas, atuais e históricas. Não é por acaso que a opressão tenta apagar estas experiências.

Outra condição é evidentemente trabalhar no coletivo e abdicar de caminhos egocêntricos. Finalmente, acessar as possibilidades utópicas presentes na arte e na cultura alternativas. Aquilo que muitas vezes foi destruído na experiência social sobrevive "armazenado" na arte (alternativo aqui significa aquilo que não está ligado aos valores ou práticas de reprodução do capitalismo ou aquelas opressivas de qualquer natureza, como já foi colocado). Por isto, logo abaixo será defendido o uso da cultura e da arte como uma etapa importante da metodologia libertadora, se é que podemos dizer que existe uma.

\section{Algumas sugestões para a libertação das práticas}

Finalmente, para concluir este texto, gostaria de expor algumas sugestões que possam contribuir para a construção metodológica de práticas de educação popular inspiradas pelas teorias da libertação, pelo menos na forma em que eu as entendo. Digo inspirar aqui, porque não creio haver uma metodologia rígida neste paradigma, independentemente do contexto de trabalho e dos desejos e características do grupo popular com o qual vamos trabalhar. Isto seria a própria negação de alguns princípios analisados nas páginas anteriores, como aquele que defende a construção coletiva do caminho e dos objetivos do trabalho social. 
Além disto, o esquema exposto abaixo não cabe integralmente em algumas situações com finalidade já constituída. Tomando estes cuidados e bastante inspirado no pensamento de Paulo Freire e na minha própria experiência com o trabalho social, creio que podemos visualizar o seguinte esquema:

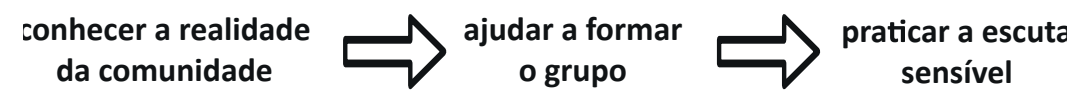$$
\checkmark \begin{aligned}
& \text { detonar o diálogo } \\
& \text { problematizador }
\end{aligned} \begin{gathered}
\text { enriquecer a discussão com o auxílio } \\
\text { de conhecimentos científicos, teorias políticas, } \\
\text { filmes, teatro, poesia, cordel, música }
\end{gathered}
$$

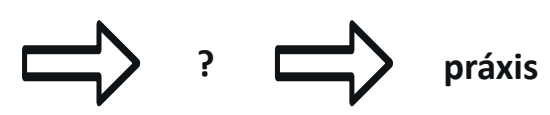

A etapa marcada com uma interrogação é quando o grupo define uma necessidade prioritária e são escolhidos os objetivos e os meios necessários para alcançá-los. Os mediadores precisam estar na posição de assessores, enquanto o grupo é o protagonista da experiência. O que virá em seguida - a práxis e seus desdobramentos - é imprevisível e precisa sê-lo, principalmente para os mediadores. Caso contrário, provavelmente estará havendo dirigismo e condução do processo pelos mediadores e pela instituição que os mantém, com metas pré-estabelecidas.

Não obstante a riqueza deste esquema metodológico, ele apresenta dois dilemas, no mínimo. O primeiro, no caso de equipes e instituições que precisam de apoio financeiro, é que a maioria das agências financiadoras exigem nos seus editais algumas definições pré-estabelecidas, como o tema e objetivos do trabalho que será desenvolvido. Surge então o dilema: não serão as metodologias libertadoras, como a exposta acima, incompatíveis com algumas exigências práticas? Não será o financiamento externo inconciliável com um principio fundamental do projeto ético-politico da libertação, que é a autodeterminação popular, essencial à autolibertação popular?

Creio que este dilema pode ser superado, pelo menos em uma certa maioria de casos. É claro que ele tem um limite, que é o caráter político da instituição financiadora. Se ela está ligada ao capital, como no caso do terceiro setor, haverá provavelmente incompatibilidade. Mas há uma grande quantidade de entes financiadores com outro caráter 
político, como os estatais, ou os organismos internacionais, ou as ongs internacionais, ou ainda aqueles ligados aos setores progressistas das igrejas. Nestes casos, muitas vezes a dificuldade é metodológica, como o dilema aqui apresentado, e não necessariamente de caráter político.

A solução está, como muitas equipes vem fazendo por todo o Brasil e América Latina, em iniciar o trabalho com o grupo ou comunidade popular, antes de submeter o projeto à agência financiadora. Ao perceber que a comunidade já define suas prioridades e por quais objetivos e direitos quer lutar, então se inicia a construção do projeto escrito, sempre que possível com o auxílio da comunidade. Só então, se buscam as agências e editais que tenham compatibilidade temática e ideológica com as demandas daquele grupo popular.

Alguém poderá argumentar: "Mas esta parte toda inicial não é remunerada. Como a equipe de trabalhadores sociais irá sobreviver até o edital ser aprovado?" Ora, sabemos que na área social, especialmente a partir das reformas neoliberais dos anos 1990 na América Latina, as equipes trabalham em projetos diferentes ou sucessivos, e que algum trabalho prévio voluntário está sempre nas suas agendas. A solução acima, portanto, não é impossível. Mas trabalhar com as metodologias libertadoras exige de nós posturas e preparação diferentes na nossa construção histórica e pessoal moderna.

Um segundo dilema que se apresenta diz respeito também ao processo de autodeterminação popular, e ele é grave. Ao estimularmos e respeitarmos o processo da comunidade, não corremos o risco de apoiar e mediar objetivos, construídos por ela, que colidem frontalmente com os processos libertadores? Não podemos esquecer que o povo, da mesma forma que nós, está inserido em uma sociedade capitalista. Mesmo os grupos mais autônomos e com consciência crítica desenvolvida tem, por assim dizer, a sociedade dentro de si, o mundo dentro de si. A superação de elementos opressivos na subjetividade é um processo que dura anos.

Trabalhar com o projeto da libertação não significa que qualquer coisa vale, pelo fato de ser um desejo popular. Há desejos populares conservadores ou ilusórios, como há também na classe média. Este é um dilema que atinge a alma dos agentes sociais da linha libertadora, e tenho visto soluções equivocadas em alguns casos, na minha percepção. $\mathrm{O}$ conjunto de objetivos e metas desejáveis pela população que podem ser acolhidos em um trabalho libertador é grande, muito mais extenso que 
em outros paradigmas, inclusive críticos. Mas este conjunto tem um limite, ele não é infinito. Este limite acaba quando aquele desejo ou objetivo não é humanizador ou libertador, mesmo que escolhido pelo grupo popular.

Este é o limite ontológico do paradigma libertador, o ponto a partir do qual ele deixa de ser o que é. Neste caso, a postura da equipe não deveria ser impor outro desejo ao grupo, mas ajudá-lo a perceber as características opressivas ou conservadoras de seu desejo. Ajudá-lo a desconstruir a sociedade dentro de si. Caso este processo não avance, e o grupo esteja irredutível, o mais coerente com um projeto ético-libertador é desistir daquele trabalho, em vez de apoiar objetivos desta natureza. Mas é essencial fazê-lo indicando claramente os motivos da nossa desistência.

\section{Referências}

DUSSEL, Enrique. Filosofia da libertação: crítica à ideologia da exclusão. São Paulo: Paulus, 2005.

DUSSEL, Enrique. Método para uma filosofia da libertação: superação analética da dialética hegeliana. São Paulo: Loyola, 1986.

FREIRE, Paulo. Educação como prática da liberdade. Rio de Janeiro: Paz e Terra, 2001.

FREIRE, Paulo. Pedagogia do oprimido. Rio de Janeiro: Paz e Terra, 1987. MOGILKA, Maurício. A educação popular e algumas problemáticas das práticas de transformação social. Revista Educação e Emancipação. São Luís, v.8, n. 2, p. 105-121, jun/dez. 2015. Disponível em: http://www. periodicoseletronicos.ufma.br/index.php/reducacaoemancipacao/ article/view/4218/2242. Acesso em: 13.01.2019

MOGILKA, Maurício. Repensar a democracia. PRACS: Revista Eletrônica de Humanidades do Curso de Ciências Sociais da UNIFAP. Macapá, v.7 n. 1, p. 61-81, jan/jun. 2014. Disponível em: https://periodicos.unifap. br/index.php/pracs/article/view/1015/Mogikav7n1.pdf. Acesso em: 13. 01.2019.

Recebido: Abril/2019

Aceito: Janeiro/2020 